\title{
Analysis on the Urban Public Art
}

\author{
Haoxin Wang \\ School of Art and Design \\ Huanghe Science and Technology College \\ Zhengzhou, China 450046
}

\begin{abstract}
The path for the development from the urban public art to the urban art is explored through analysis on the nature of urban public art and thinking on the development of it. This paper analyzes the nature of urban public art and explores the development trend of it through the literature analysis, theoretical analysis, case analysis and comparative analysis. The nature of urban public art is embodied in the material, spirit, aesthetic appreciation, emotional characteristics, creativity, commonality, life feature, political nature, site property and innovation, which make the development of urban public art systematic, layered and diversified as well as successive, epochal and innovative, embodying in the functions of the city and people's life and making the city become artworks. The urban public art develops into the urban art through the integration in the overall aesthetic environment of the city.
\end{abstract}

Keywords-urban public art; the nature of art; the nature of public art; development; urban art

\section{INTRODUCTION}

In recent years, with the soaring development of Chinese cities, the circle of art and design pays attention to the urban public art. At present, it is uncertain about the orientation, the boundary division and the development of public art. Therefore, it is necessary to analyze the nature of urban public art, so as to explore the development path of it.

\section{THE NATURE OF ART}

The research on the urban public art should base on the understanding of the nature of art. The definition of art in $\mathrm{Ci}$ $H a i$ is "a special way for people to understand the world through emotion and imagination, namely represent the reality and express the emotional ideal as well as realize the mutual objectification of aesthetic subject and object." In English, art means "artificial production". The beauty is divided into the realistic beauty and the artistic beauty. The artistic beauty is independent from the realistic beauty and the beauty of the natural world, embodying people's physical and spiritual creation. In regard to the nature of art, $\mathrm{Mr} \mathrm{Li}$ Xinfeng describes in his article of Discussion on Looking the Nature of Art from the Perspective of Marx's Theory of Artistic Production, "art is the reflection of the nature of social life; art is a social ideology of superstructure; art is a special form of production, a practice form and a spiritual production; art has aesthetic characteristics; art has strong emotional features; art has the prominent characteristics of imagination". [1] According to the definition and nature of art, it shows art is the creature full of people's wisdom and imagination, reflecting the objective world including the human society and the idea of people, politics, society and the aesthetic demand in life. The value of it is realized in people's emotional experience. The nature of artistic beauty is independent from the natural world and reflects the material and spiritual world created by people, paying attention to the aesthetic experience of humanistic material and spirit.

\section{ANALYZE THE NATURE OF URBAN PUblic ART}

The public art is the art of the public or society. It exists in the public space and serves the public, reflecting the life value of culture opening, sharing and communication in the public space. [2] City is a complex formed by the social power and historic culture of human beings and has the functions and practical meaning of human society, showing all the important meanings of human civilization. It combines human society with cultural cluster, referring to the most complicated human material and spiritual system, the complex of artificiality and the complex of relation between human and the artificiality. It shows the city has the essential property of art. Its substantive characteristics embody in the materiality, spirituality, aesthetic appreciation, emotional characteristics, creativity, commonality, life features, political nature, site property and development as well as the urban overall environment.

\section{A. The IntrinsicalMateriality of Urban Public Art}

Art is one of the meaningful and comprehensive production activities. Marx thinks "art" is a particular form of production activity and dominated by the universal rule of production, which cannot do without the material carrier. The production of art also needs the material carrier, showing the materiality of the nature of art, which is shown by the city more prominently. Initially, the city is the most complicated material system of human society that reflects functional demands including the aesthetic appreciation in human's social life. Buildings are the first and foremost element of cities and the typical example for the materiality of the nature of urban art, because it is the material carrier with the organic integration of people's residence, emotion and aesthetic appreciation. Hegel once said buildings are the start of art history.

\section{B. The Intrinsical Spirituality of Urban Public Art}

Objective matters are the subjective spiritual carriers among artificiality in the cities. The spirit cannot separate from the material. The urban material life and spiritual life are inseparable because people often create in the production activities according to their aesthetic experience. Spiritual life 
is the essential requirement of human nature. The creation of urban public art is the creation of spiritual wealth based on the material production. The value embodies in the process of aesthetic experience of urban public art. The typical artistic forms include urban sculpture, urban murals, urban media, urban landscape and urban gardening.

\section{The IntrinsicalAesthetic Appreciation of Urban Public Art}

Beauty and aesthetic appreciation are the nature of art, which is extensive in the society formed by people's material and spiritual world. Therefore, the plan, design and facilities of modern cities must have rules of aesthetic appreciation. Varies of material carriers of the city pursue the rules of beauty, even the cities may become the integral artwork. For example, the Dali Old City and the Old Town of Lijiang in Yunnan show the integrated artistic characteristics. "Fig. 1", "Fig. 2"

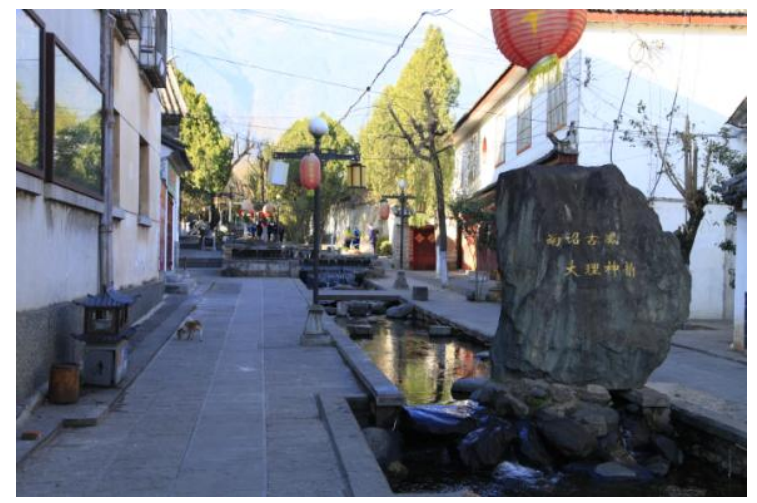

Fig. 1. The Old City Dali

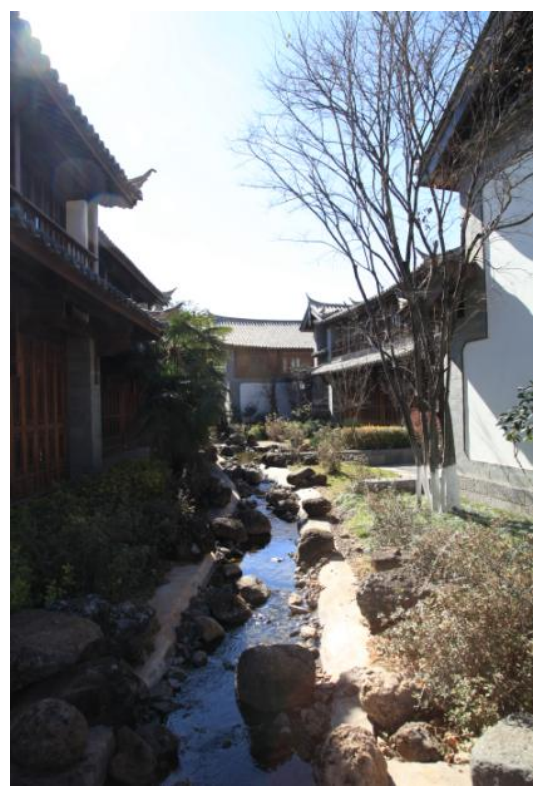

Fig. 2. The Old Town Lijiang

The artistic beauty of city is the embodiment of the realistic aesthetic attributes of art, referring to the aesthetic object as well as the objective of artistic creation. It should pay attention to the internal essence and the external phenomenon, forms and characteristics of the cities. For example, the overall landscape environment of Suzhou History Museum designed by Mr. leoh Ming Pei has strong features of artistic aesthetics. "Fig. 3"

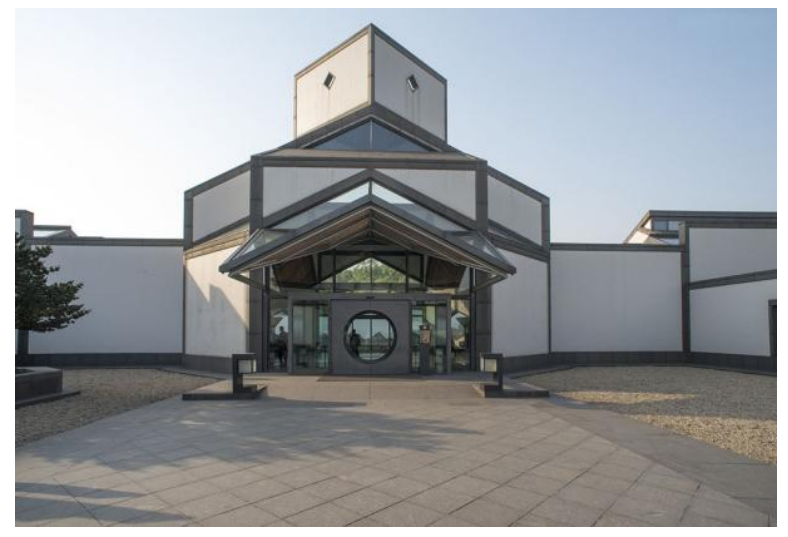

Fig. 3. Suzhou History Museum

\section{The IntrinsicalEmotional Characteristics of Urban Public Art}

Urban art is the medium of public aesthetic judgment, concentrating the emotion of citizens and embodying the participation of the public. [3] Emotion refers to people's psychological forms like pleasure, anger, sorrow and joy. All arts are emotional. Art cannot separate from the emotion, so do the urban art. The city is the gathering place of human and society. Its residence and environment integrate in human emotion and run through the aesthetic process in human life and people's artistic creation namely the urban construction. The emotion reflects in the aesthetics of urban art and organically integrates with the urban history, culture, image, ecology and environment. For example, the Qijiang Park in Guangdong is a creation of an old shipyard, embodying the organic relations of history, culture, image, ecology and environment as well as people's nostalgic, cultural and natural emotions and concentrating in the specific application of environment, buildings, traffic route, landscape facility and urban media. For example, the footprint relief Road in Dalian Xinghai Square is formed by the footprints of one thousand Dalian citizens, reflecting the urban development of nearly one hundred years and fully integrating the urban emotion of citizens. "Fig. 4"

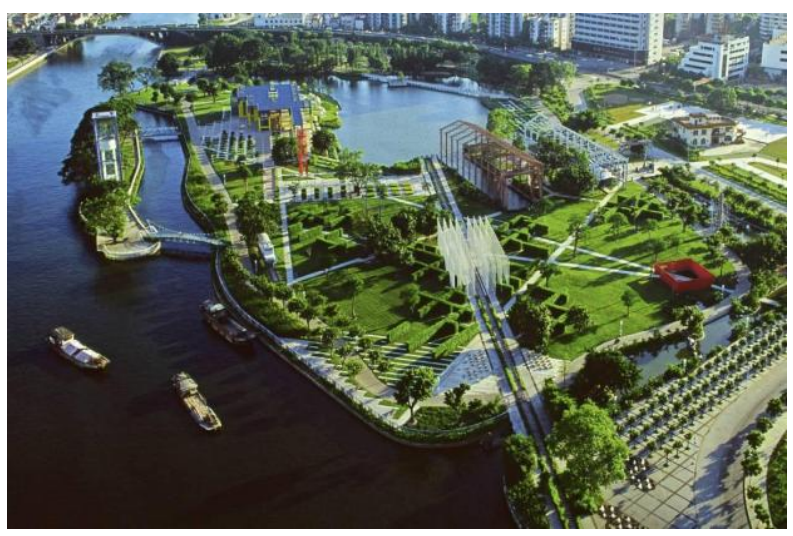

Fig. 4. Qijiang Park 


\section{E. The IntrinsicalCommonality of Urban Public Art}

The commonality of the city represents the nature of it, determining the commonality of urban art, which is the substantive characteristic of urban art. It is people's basic appeal for modern urban space environment and becomes people's lifestyle. For example, people sing and dance in squares and parks, appreciate the urban history, culture and ecological landscape and take a leisurely life in the beautiful urban environment, hoping to communicate in the art environment of public space and enjoy the common beauty. The aesthetic activities of the external artistic forms in cities run through the urban environment and people's emotional pleasure and life. The ownership of the application function doesn't influence the perceptual representation of the public spirit of urban art. For example, the buildings in cities have specific ownership, but the artistic attributes of external forms, size, structure, material and color are common, participating in people's aesthetic activities.

\section{F. The IntrinsicalLife Feature of Urban Public Art}

The art roots in and reflects the social life as well as the material and spiritual life. In the Marxist philosophy, the art shows as the economic foundation and the superstructure. Similarly, the life feature of urban art reflects the materiality of cities as the economic foundation, the spirituality of it as the superstructure in urban life. Life refers to all the social activities of people for existence. The activities cannot do without the different urban environment, buildings, life tools, work objects and emotions, which belong to the urban public art. It shows the urban life has strong appeal for art and beauty. The artistry of life is the original pursuit of modern city. The urban public art closely relates to life, no matter in buildings, facilities, blocks and ecology.

\section{G. The Intrinsical Site Property of Urban Public Art}

Urban art is the complicated system integration. From the perspective of space composition, the city is formed by path, boundary, area, node and marks. The site refers to the big or small areas in cities. The site property means the typical characteristics of the areas are identified. The site property of urban art refers to the typical characteristics of mechanism, space, details of forms, signs, terrain, materials, styles, decoration, color and outline in the urban region. For example, the Xintiandi in Shanghai has clear typical characteristics in architectural form, space composition, the detailed decoration of buildings, regional features, and color of the mechanism, environmental facilities and art facility. "Fig. 5" The site property of urban art is the essential property. A city is formed by different relatively independent features of sites, which enrich the urban art and form the aesthetic experience with plentiful layers.

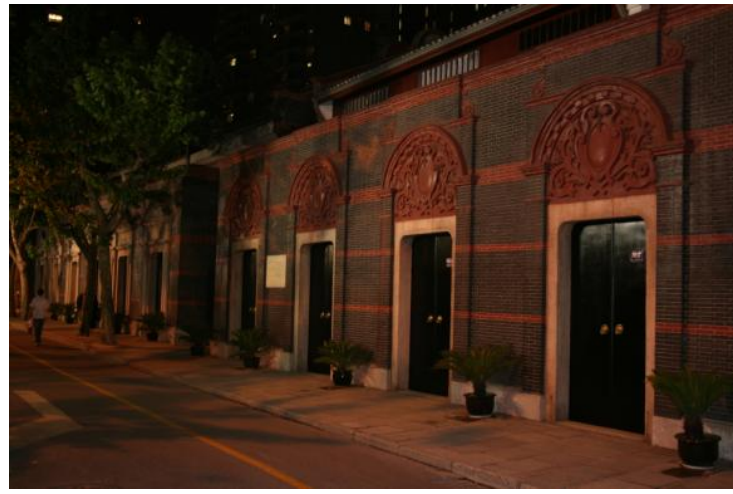

Fig. 5. Xintiandi in Shanghai (shoot by self)

\section{H. The Intrinsical Political Nature of Urban Public Art}

According to Marx's philosophical theory, as the supreme form of superstructure, the politics has certain influence on art. The economic foundation and the art influence each other through the politics. The city is the most complicated and systematic social carrier. The political nature of urban art embodies in: a. the historic culture of urban development. For example, the Huangdi Mausoleum of China designed by Mr. Zhang Jinqiu, the famous master architect, fully embodies the political nature of public art "Fig. 6"; b. the memorial landscape of urban public space. For example, the Vietnam War memorial landscape in Washington has V type downward passage with the names of the deceased engraved on the two black marble walls, having profound commemorative significance "Fig. 7"; c. the urban development. The urban planning in feudal society embodies the imperial power. The modern urban planning reflects the humanistic concern of democratic society and the service for citizens.

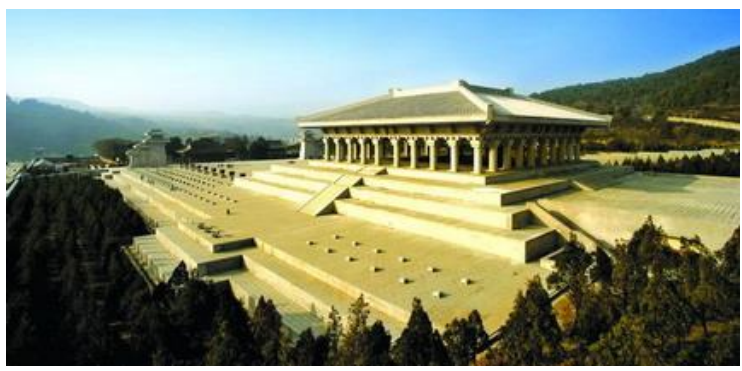

Fig. 6. Huangdi Mausoleum of China

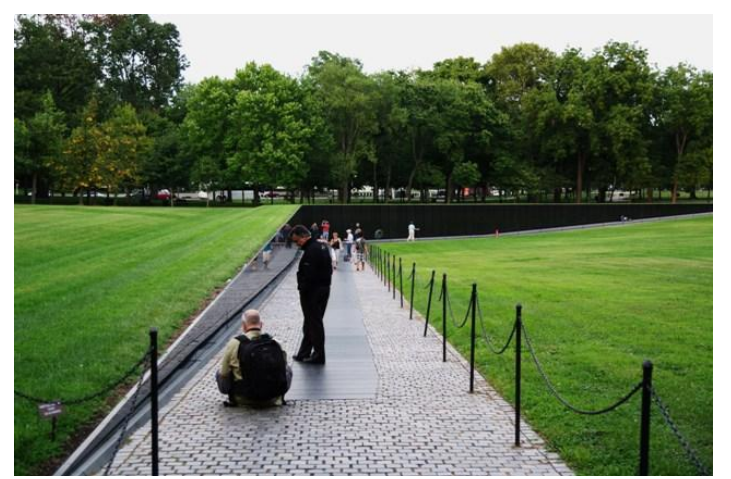

Fig. 7. The memorial landscape in Washington, DC, USA for Vietnam War 


\section{The Intrinsical Innovation of Urban Public Art}

As an artistic form, the urban public art connects the spirit and material, the aesthetic appreciation and emotion, the philosophy and science and technology. Its innovation firstly refers to the innovation of artistic concepts and methods, and then the innovation of science and technology and itself. The innovation of artistic concepts makes the urban public develop from the memorial, narrative, aesthetic and decorative into the functional, diversified and comprehensive. The forms of urban art also develop form the sculpture and wall painting to the buildings, blocks, ecology, facilities and media. The innovation relates to the idea, science and technology as well as art, including the connotation, forms and applications. The achievements of innovation reflect in the phenomenon of urban public art.

\section{THE THINKING ON THE DEVELOPMENT OF URBAN PUBLIC ART}

The thinking on the nature of art directly relates to the endless exploration on the significance of people's existence. The development of the nature of art shows in the continuous setout and the discovery of new realm. [4] The development of urban art shows as the inheritance, epochal character and innovation of the development of artistic rules. Inheritance is the premise of the urban art development. Firstly, without inheritance, the art will lose its coordinates of development. Secondly, the art is rooted in human society and race culture. The social and cultural differences are the premise of artistic difference. The difference and individuality are the life of art. For example, the waterside ancient city in Suzhou and the quadrangle dwellings of Beijing are typical examples of cultural inheritance. Hippolyte Adolphe Taine, the renowned French literary theorist, addressed in revealing the reasons of artistic development in the Philosophy of Art, "Art is determined by the spirit of the time and custom." [5] It shows the artistic development relates to the time. As the superstructure, the art becomes the direct reflection of economic foundation. The social economy determines the corresponding art forms and contents. Innovation is the life of the urban artistic development. Innovation makes the art become more and more technological. The digital media, network media, experience art and holographic technique are applied to the urban public art more extensively. For example, the interesting Crown Fountain in the Millennium Park of Chicago is the typical case for the application of information technology in the urban public art "Fig. 8". The "commonality" of urban public art is relative. Relative to the interior space, the buildings are common. Relative to the buildings, the functional areas like the schools, institutions, residence zones and factories are common. Relative to the schools, institutions, residence zones and factories, the streets, squares and parks in cities are common. It shows the public boundary is uncertain dynamically. The uncertainty makes the urban public art extensive, which makes the cities become artworks. It contradicts to the urban public art in the relative environment. In order to solve the contradiction, it is necessary to enrich the connotations of urban public art, making it develop from the opposition to the integration of environment, from the original artistic phenomenon to the systematic urban aesthetic appreciation and pay attention to the material, spirit, aesthetic appreciation, emotional characteristics, creativity, commonality, life feature, political nature and site property of art. Besides, its development should be systematic, layered and diversified, integrating in the functions of the city, the life of citizens, the overall aesthetic environment of the city, the national, cultural and historical emotion, the humanistic concern and public participation, far beyond the aesthetic appreciation, emotional characteristics and spirituality opposite to the environment. The aesthetic experience develops into the experience of ecology and city, land art, environment and site, urban and architectural forms, urban context as well as social culture and life. The city becomes the artwork created by the law of beauty. Life becomes a part of the urban artistic activities. At this time, the concept of urban public art loses its significance, replaced by the concept, category and connotation of urban art.

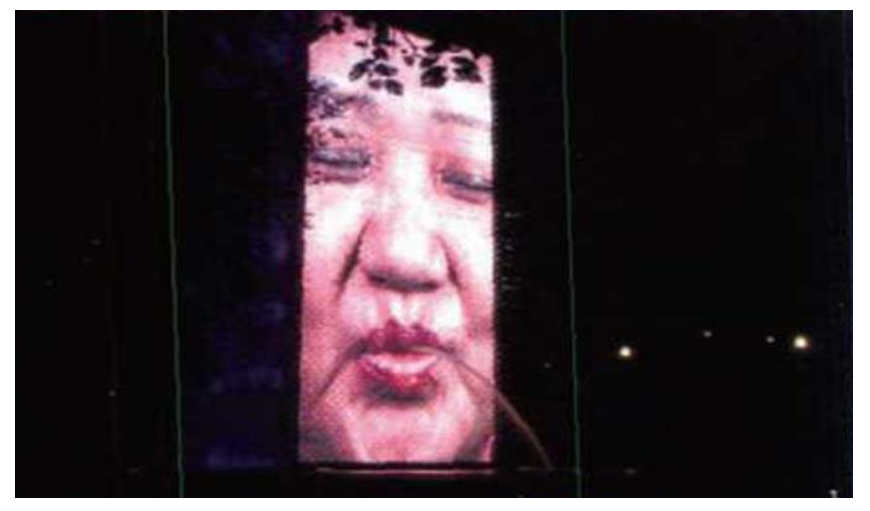

Fig. 8. Crown Fountain in the Millennium Park

\section{CONCLUSION}

The nature of urban public art is embodied in the material, spirit, aesthetic appreciation, emotional characteristics, creativity, commonality, life feature, political nature, site property and innovation, which make the development of urban public art systematic, layered and diversified. It develops from the opposition to the integration of environment and embodies in the overall spatial arrangement, architectural form, urban context and social culture as well as the life experience. The concept of the urban public art becomes increasingly vague without certain form, developing into the urban art.

\section{REFERENCES}

[1] Li Xinfeng. Discussion on Looking the Nature of Art from the Perspective of Marx's Theory of Artistic Production, Literature and Art Forum [J], the 6th issue of 1991: 18, Literature and Art Studies [J]], 2010, 06: 115

[2] Song Wei. Public Art and Urban Culture, Literature and Art Criticism [J], 2006, 6: 92

[3] Wang Baohua, Yang Haozhong, Zhang Bin. Discussion on the Value of Urban Public Art [J], Journal of Northwest University (Philosophy and Social Sciences Edition), the 41st volume of Sept. 2011, the 5th issue: page 171

[4] Zhong Hua. Mistake in Ways of Pursuing the Nature of Art [L], Academic Monthly, the 39th volume of Dec. 2007: 97 
[5] Wang Feng, Guo Weimin. Exploration on the Media Materials and Space of the Digital Urban Public Art [L], Decoration, the 211th issue of Nov. 2010: page 104. 